\title{
The status of the Diplosentidae (Acanthocephala: Palaeacanthocephala) and a new family of acanthocephalans from Australian wrasses (Pisces: Labridae)
}

\author{
Sylvie Pichelin and Thomas H. Cribb
}

Department of Microbiology and Parasitology, The University of Queensland, Brisbane, Queensland, 4072, Australia

Key words: Transvena, Trajectura, Diplosentis, Neorhadinorhynchus, Sclerocollum, fish

\begin{abstract}
The status and composition of the Diplosentidae Tubangui et Masiluñgan, 1937 are reviewed. The type species of the type genus, Diplosentis amphacanthi Tubangui et Masiluñgan, 1937 from Siganus canaliculatus (Park, 1797) in the Philippines, is concluded to have been described inaccurately in supposedly possessing only two cement glands and lemnisci enclosed in a membranous sac. The species is almost certainly very close to species of Neorhadinorhynchus Yamaguti, 1939 and Sclerocollum Schmidt et Paperna, 1978 which have also been reported from siganids from the tropical Indo-Pacific. Species of these genera have four cement glands and unexceptional lemnisci. As a result, Diplosentis Tubangui et Masilungan, 1937 is best considered to have affinities with the Cavisomidae Meyer, 1932. The Cavisomidae has priority over the Diplosentidae; thus the Diplosentidae becomes a synonym of the Cavisomidae. Neorhadinorhynchus and Sclerocollum are considered synonyms of Diplosentis. The affinities of the other species and genera formerly included in the Diplosentidae (other species of Diplosentis, Allorhadinorhynchus Yamaguti, 1959, Amapacanthus Salgado-Maldonado et Santos, 2000, Pararhadinorhynchus Johnston et Edmonds, 1947, Golvanorhynchus Noronha, de Fábio et Pinto, 1978 and Slendrorhynchus Amin et Sey, 1996) are discussed. It is concluded that all but Pararhadinorhynchus, two species of Diplosentis and Amapacanthus can be accommodated elsewhere satisfactorily. A new family, Transvenidae, is proposed for a small group of acanthocephalans that genuinely possess only two cement glands. Transvena annulospinosa gen. n., sp. n. is described from the labrids Anampses neoguinaicus Bleeker, 1878 (type host), A. geographicus Valenciennes, 1840, A. caeruleopunctatus Rüppell, 1829, Hemigymnus fasciatus (Bloch, 1792), and $H$. melapterus (Bloch, 1791) from the Great Barrier Reef, Queensland, Australia. Transvena gen. $\mathrm{n}$. is distinguished from all other acanthocephalan genera by having a combination of a single ring of small spines on its trunk near or at the junction between the neck and trunk, two cement glands, a double-walled proboscis receptacle and hooks which decrease in length from the apex to the base of the proboscis. A second new genus within the Transvenidae, Trajectura, is proposed for T. perinsolens sp. $\mathrm{n}$. from Anampses neoguinaicus, also from the Great Barrier Reef. Trajectura gen. $\mathrm{n}$. is distinguished by the possession of only two cement glands and an anterior conical projection (function unknown) on the females. Diplosentis ikedai Machida, 1992 shares these characters and is recombined as Trajectura ikedai comb. n. Pararhadinorhynchus is transferred to the Transvenidae and Diplosentis manteri Gupta et Fatma, 1979 is recombined as Pararhadinorhynchus manteri comb. n.
\end{abstract}

Specimens of acanthocephalans were recovered from wrasses (Labridae) from Heron Island, on the southern Great Barrier Reef, Australia. They were initially thought to belong to the Diplosentidae Tubangui et Masiluñgan, 1937 because they possessed only two cement glands. However, it became apparent while reviewing the literature on this family, that the type species, Diplosentis amphacanthi Tubangui et Masiluñgan, 1937, bore an interesting resemblance to the type species of Sclerocollum Schmidt et Paperna, 1978, a member of the Rhadinorhynchidae Travassos, 1923. Upon further investigation, species of Sclerocollum were also found to resemble closely some species of Neorhadinorhynchus which is currently in the Cavisomidae Meyer, 1932. Here we review these taxa.

\section{MATERIALS AND METHODS}

Acanthocephalans were removed from the intestines of fish, placed in tap water until the proboscis everted, then fixed in a diluted Berland's fluid ( $1 \mathrm{ml}$ of $95 \%$ glacial acetic acid and $5 \%$ formalin diluted in $10 \mathrm{ml}$ of tap water) and stored in $70 \%$ ethanol or $10 \%$ formalin. Specimens were stained with Mayer's haematoxylin, dehydrated through a graded series of alcohols, cleared with methyl salicylate and mounted in Canada balsam. Some specimens were sectioned at $7 \mu \mathrm{m}$ and stained with haematoxylin and eosin. Some specimens were critical point dried, sputter coated with gold and viewed using a JEOL JSM-6300F scanning electron microscope operated at $10 \mathrm{kV}$. Authorities and classification of fishes are according to FishBase (2000).

Drawings were made with the aid of a camera lucida. Measurements, presented as the range with the mean in parentheses, are given in micrometres. Abbreviations used: AHC - Australian Helminthological Collection, South Australian Museum, South Australia, Australia; AM - The Australian Museum, New South Wales, Australia; IPCAS Institute of Parasitology, Academy of Sciences, České Budějovice, Czech Republic; MPM - Meguro Parasitological Museum, Tokyo; BMNH - The British Museum, Natural 
History collection at The Natural History Museum, London, UK; NSMT - National Science Museum, Tokyo; QM Queensland Museum, Queensland, Australia; USNPC United States National Parasite Collection, Beltsville, Maryland, USA.

Museum specimens examined: Diplosentis amphacanthi cotypes (USNPC 37668); Diplosentis ikedai holotype (NSMTAs 2157 1/5), paratypes (NSMT-As 2157 3/5; NSMT-As 2157 4/5); Pararhadinorhynchus coorongensis "types" (AHC 42392-42393), paratypes (AHC 42381-42391, 42394-42398) and vouchers (AHC 18801, 20638, 27802-27804); Pararhadinorhynchus mugilis holotype (AHC 42399), paratypes (AHC 42400-42421) and vouchers (AHC 42422-42425 sections); Micracanthorhynchina segmentata holotype, "allotypes" and paratypes (MPM 22041) and vouchers (NSMT-As 122; NSMT-As 477); Neorhadinorhynchus aspinosus vouchers (MPM 22091; MPM 22099); Pseudogorgorhynchus arii paratypes (IPCAS A-63); Sclerocollum rubrimaris paratypes (USNPC 73897-73898); Sclerocollum robustum "types" (AM W3796); Slendrorhynchus breviclaviproboscis paratypes (USNPC 85955).

\section{RESULTS}

The family Diplosentidae Tubangui et Masiluñgan, 1937 was established by Tubangui and Masiluñgan (1937) for Diplosentis amphacanthi Tubangui et Masiluñgan, 1937 which was described in the same paper. The family was characterised by the absence of trunk spines, presence of just two cement glands, heavily coiled lemnisci said to be enclosed in a membranous sac and similar hooks on the proboscis. The species was described from numerous specimens collected in the Philippines from Amphacanthus oramin, a siganid species synonymous with Siganus canaliculatus (Park, 1797), which occurs widely in the tropical Indo-Pacific. Subsequent to the description of $D$. amphacanthi, just two further species have been reported in the genus: D. manteri Gupta et Fatma, 1979 was described from a single specimen from an ariid catfish in India by Gupta and Fatma (1979) and $D$. ikedai Machida, 1992 was described from 11 specimens from a labrid fish in Japan by Machida (1992).

The subsequent taxonomic history of the family is complex and unsatisfactory. It has not been reviewed or revised recently. The family is now generally considered to be represented by ten species in six genera in two subfamilies (Table 1). Johnston and Edmonds (1947) proposed Pararhadinorhynchus Johnston et Edmonds, 1947 which Golvan (1969) placed in the Diplosentinae Tubangui et Masiluñgan, 1937 of the Diplosentidae along with Diplosentis Tubangui et Masiluñgan, 1937 because they had two cement glands and no trunk spines. Golvan (1969) also created the Allorhadinorhynchinae Golvan, 1969 based on Allorhadinorhynchus Yamaguti, 1959, for diplosentids with two cement glands and trunk spines. Subsequently Noronha et al. (1978) added Golvanorhynchus Noronha, de Fábio et Pinto, 1978, Amin and Sey (1996) added
Slendrorhynchus Amin et Sey, 1996 and finally Salgado-Maldonado and Santos (2000) added Amapacanthus Salgado-Maldonado et Santos, 2000, all within the Allorhadinorhynchinae. The addition of these genera has modified the concept of the family to include genera with more than two cement glands (Golvanorhynchus and Slendrorhynchus). The type species of Allorhadinorhynchus, A. segmentatum Yamaguti, 1959, was described by Yamaguti (1959) as having only two cement glands but Araki and Machida (1987) showed that this species possesses four cement glands and, as a result, proposed the new combination of Micracanthorhynchina segmentata (Yamaguti, 1959) which implies membership of the Rhadinorhynchidae. As a result they synonymised Allorhadinorhynchus with Micracanthorhynchina Strand, 1936. This action also had significance for the subfamily Allorhadinorhynchinae which should have fallen into synonymy, however this has not been commented on by any authors. Despite this wellargued action, Amin and Sey (1996) did not recognise the new combination proposed by Araki and Machida (1987), stating without argumentation that it was "invalid". Thus, as it stands now, the family has little morphological integrity.

The concept of the Diplosentidae depends on the nature of the type species of the type genus, Diplosentis amphacanthi. Figures in the original description of the species show contracted specimens; the proboscis is probably retracted in all the specimens (although not inverted) and the interpretation of the cement glands and lemnisci appears questionable. Type specimens of this species were deposited in the Philippine Bureau of Science Parasitological Collection as lot No. 504 by Tubangui and Masiluñgan (1937). Unfortunately these specimens were destroyed during the second World War (Eduardo 1997) but cotypes were lodged in the USNPC. The lemnisci in these cotypes are contracted appearing coiled but not enclosed in a membrane. The condition of the specimens precluded determining with certainty whether these specimens had two or four cement glands. No further specimens of this species have been collected from the Philippines (Arthur and Lumanlan-Mayo 1997) and there have been no new reports of this species in the literature. Two other genera of acanthocephalans known from siganids bear importantly on our understanding of this species.

Neorhadinorhynchus Yamaguti, 1939 was erected by Yamaguti (1939) as a subgenus of Rhadinorhynchus Lühe, 1911 for $R$. (N.) aspinosus (Fukui et Morisita, 1936) which had been described as Rhadinorhynchus aspinosus from Teuthis fuscescens (now Siganus fuscescens (Houttuyn, 1782)). Yamaguti (1939) reported eight specimens of what he interpreted as being the same species from the acanthurid Xesurus scalprum (now Prionurus scalprum Cuvier et Valenciennes, 1835). We have been unable to locate the holotype of Neorhadinorhynchus aspinosus but have examined 
Table 1. List of species belonging to the Diplosentidae according to Amin and Sey (1996) and Salgado-Maldonado and Santos (2000). In the present study, the Diplosentidae is considered a synonym of the Cavisomidae. Several further taxonomic changes are also proposed.

\begin{tabular}{|c|c|c|c|}
\hline Parasite & Host & Host family & Reference \\
\hline Allorhadinorhynchus segmentatum Yamaguti, 1959 & Hyporhamphus sajori (Temminck et Schlegel, 1846) & Hemiramphidae & Yamaguti (1959) \\
\hline Amapacanthus amazonicus Salgado-Maldonado et Santos, 2000 & $\begin{array}{l}\text { Arius passany (Valenciennes, } 1840 \text { ) } \\
\text { Anableps microleps Müller et Troschel, } 1844\end{array}$ & $\begin{array}{l}\text { Ariidae } \\
\text { Anablepidae }\end{array}$ & Salgado-Maldonado and Santos (2000) \\
\hline Diplosentis amphacanthi Tubangui et Masiluñgan, 1937 & $\begin{array}{l}\text { Siganus canaliculatus (Park, 1797) } \\
\quad \text { (as Amphacanthus oramin) }\end{array}$ & Siganidae & Tubangui and Masiluñgan (1937) \\
\hline Diplosentis ikedai Machida, 1992 & Cirrhilabrus cyanopleura (Bleeker, 1851) & Labridae & Machida (1992) \\
\hline Diplosentis manteri Gupta et Fatma, 1979 & Arius arius (Hamilton, 1882) & Ariidae & Gupta and Fatma (1979) \\
\hline Golvanorhynchus golvani Noronha, de Fábio et Pinto, 1978 & Scomber colias Gmelin, 1789 & Scombridae & Noronha et al. (1978) \\
\hline Pararhadinorhynchus mugilis Johnston et Edmonds, 1947 & Mugil cephalus Linnaeus, 1758 & Mugilidae & Johnston and Edmonds (1947) \\
\hline Pararhadinorhynchus coorongensis Edmonds, 1973 & Aldrichetta forsteri (Valenciennes, 1836) & Mugilidae & Edmonds (1973) \\
\hline Pararhadinorhynchus upenei Wang, Wang et Wu, 1993 & Upeneus sulphureus Cuvier, 1829 & Mullidae & Wang et al. (1993) \\
\hline Slendrorhynchus breviclaviproboscis Amin et Sey, 1996 & $\begin{array}{l}\text { Lagocephalus lunaris (Bloch et Schneider, 1801) } \\
\text { Leiognathus bindus (Valenciennes, 1835) }\end{array}$ & $\begin{array}{l}\text { Tetraodontidae } \\
\text { Leiognathidae }\end{array}$ & Amin and Sey (1996) \\
\hline
\end{tabular}


Yamaguti's specimens. The description by Fukui and Morisita (1938) states that the species has four cement glands. Yamaguti (1939) defined the subgenus as having four cement glands and examination of his specimens confirms this. Yamaguti (1939) also combined a second species, $R$. (N.) nudus Harada, 1938 from Trachurus japonicus (Temminck et Schlegel, 1844), with this subgenus. Yamaguti (1963) later raised the subgenus to full genus status within the Echinorhynchidae and the subfamily Cavisomatinae. In addition to the two original combinations, four further species of Neorhadinorhynchus have been proposed. One of these, N. macrospinosus Amin et Nahhas, 1994, is of particular interest as it was described by Amin and Nahhas (1994) from Siganus vermiculatus (Valenciennes, 1835) (as S. vermicularis [sic]) albeit from a single juvenile female. Neorhadinorhynchus is presently considered to belong to the Cavisomidae, presumably on the basis of the lack of trunk spines and the presence of four cement glands.

The other genus of interest is Sclerocollum Schmidt et Paperna, 1978 which was erected for S. rubrimaris Schmidt et Paperna, 1978 from Siganus rostratus (Quoy et Gaimard, 1825), S. rivulatus (Forsskål, 1775) and Pseudobalistes fuscus (Bloch et Schneider, 1801) (a balistid) (Schmidt and Paperna 1978). S. rubrimaris appears morphologically very similar to Diplosentis amphacanthi. However, Sclerocollum was compared only with Neorhadinorhynchus from which it was distinguished because it possessed conspicuous sclerotised plates in the anterior wall of the trunk. Schmidt and Paperna (1978) also combined Neorhadinorhynchus robustus Edmonds, 1964 with this genus. This species had been described from Siganus lineatus on the southern Great Barrier Reef by Edmonds (1964). We have examined type specimens of $S$. rubrimaris and $S$. robustum and new specimens of both these species from several siganid species and found that clearly they possess four cement glands and lemnisci without any kind of enclosing membranous sac. However, we have observed that, in specimens that have the proboscis retracted, the lemnisci are contracted and have a coiled appearance, similar to that described for $D$. amphacanthi. We also noted that the amount of plaque material in the 20 paratypes (USNPC 73897-73898) of $S$. rubrimaris examined during this study varied from specimen to specimen and that some specimens of Sclerocollum we collected have no sclerotised plate material at all. We re-examined Yamaguti's (1939) specimens of Neorhadinorhynchus aspinosus and found that they clearly possessed sclerotised plates. The implication of finding sclerotised plates on the type species of Neorhadinorhynchus (i.e. N. aspinosus) is important. It was the only character used by Schmidt and Paperna (1978) to distinguish between Sclerocollum and Neorhadinorhynchus. There is therefore no basis to consider these two genera different.
The family Siganidae contains just the single genus Siganus and 27 species distributed widely in the tropical Indo-Pacific (Woodland 1990). Sclerocollum rubrimaris and unidentified Sclerocollum have been reported from siganids in the Red Sea, the Gulf of Arabia and the coast of Kenya from Siganus argenteus, S. canaliculatus, $S$. luridus (Rüppell, 1829), S. rivulatus, $S$. rostratus and $S$. sutor (Valenciennes, 1835) (see Schmidt and Paperna (1978), Amin et al. (1984), Diamant (1989), El-Naffar et al. (1992), Martens and Moens (1995) and Geets and Ollevier (1996)). The literature on siganid parasites is extensive, but apart from the accounts of acanthocephalans from siganids dealt with above, there are only a handful of reports of acanthocephalans from siganids. These are Acanthocephalus japonicus Fukui et Morisita, 1936 from Siganus fuscescens, Japan (Yamaguti 1963), Filisoma indicum Van Cleave, 1928 from S. vermiculatus, Panaji (Gupta and Jain 1979), Neoechinorhynchus chilkaensis Podder, 1937 from S. vermiculatus, India (Gupta and Jain 1983), Longicollum pagrosomi Yamaguti, 1935 from $S$. fuscescens, locality not given (Golvan 1969) and Tenuisentis sp. from $S$. canaliculatus, Arabian Gulf (El-Naffar et al. 1992); none of these species has any resemblance to Diplosentis amphacanthi.

The only generic character that would differentiate between the types of Diplosentis, Sclerocollum and Neorhadinorhynchus is the number of cement glands and the enclosure of the lemnisci in a membranous sac. The description of Diplosentis amphacanthi is unconvincing in view of the fact that the specimens were contracted, that numerous other studies have shown such characters are easily confused, and that no acanthocephalan with two cement glands has ever been reported again from siganids. In contrast, there are many reports from all over the tropical Indo-Pacific of Neorhadinorhynchus and Sclerocollum species that resemble $D$. amphacanthi in general, but have four cement glands and unexceptional lemnisci. Furthermore, sclerotised plates could be seen in some of the cotypes of $D$. amphacanthi and the lemnisci did not appear to be enclosed in a membranous sac. The similarity in proboscis armature (i.e. arrangement in longitudinal rows, size, shape and number of hooks), the cylindrical proboscis, and the overall disposition of the male reproductive organs is striking between the type species of Diplosentis, Sclerocollum and Neorhadinorhynchus. We thus conclude that the cement glands and lemnisci of $D$. amphacanthi were described erroneously and propose that Diplosentis should be redefined.

Diplosentis Tubangui et Masiluñgan, 1937 emended

New synonyms: Neorhadinorhynchus Yamaguti, 1939; Sclerocollum Schmidt et Paperna, 1978.

Diagnosis. Cavisomidae. Trunk medium to long, largely cylindrical but with tapering ends, may be slightly dilated anteriorly, without trunk spines. Neck 
present. Proboscis cylindrical. Proboscis hooks arranged in longitudinal rows, basal hooks only slightly smaller than middle and apical hooks, no notable differences between dorsal and ventral hooks. Proboscis receptacle double-walled; ganglion about mid-proboscis receptacle. Lemnisci vary in length between species, may be coiled when proboscis retracted. Male reproductive system may occupy up to two-thirds of trunk. Testes 2 , spherical to ovoid, roughly equatorial, tandem. Cement glands 4, in two pairs, posterior pair may overlap slightly with anterior pair; pairs may be of unequal lengths. Seminal vesicle present. Säfftigen's pouch present. Eggs with polar elongation of E2 membrane. Parasites in intestines of marine fishes.

$\mathrm{T}$ y $\mathrm{p}$ e $\mathrm{s}$ p e c i e s : Diplosentis amphacanthi Tubangui et Masiluñgan, 1937. Although the type material of Diplosentis amphacanthi appears to have been destroyed in World War II (Eduardo 1997) cotypes (USNPC 37668) are still available.

I n c l u d e d s p e c i e s : All species of Sclerocollum Schmidt et Paperna, 1978 and Neorhadinorhynchus Yamaguti, 1939: Diplosentis rubrimaris (Schmidt et Paperna, 1978) comb. n., D. robustum (Johnston et Edmonds, 1964) comb. n., D. aspinosus (Fukui et Morisita, 1937) comb. n., D. atlanticus (Gaevskaja et Nigmatullin, 1977) comb. n., D. macrospinosus (Amin et Nahhas, 1994) comb. n., D. madagascariensis (Golvan, 1969) comb. n., D. myctophumi (Mordvinova, 1988) comb. n., D. nudus (Harada, 1938) comb. n.

Remarks. The similarities between the types of Neorhadinorhynchus, Sclerocollum and Diplosentis are striking. All three genera have no trunk spines, cylindrical proboscides with longitudinal rows of hooks of similar size and shape, four cement glands arranged in pairs one after the other (in light of the new proposals) and two testes arranged in tandem. We consider that Diplosentis amphacanthi possesses four cement glands and that its lemnisci were coiled tightly rather than enveloped in a membranous sac. We also consider that sclerotised plates are not restricted to Sclerocollum and that in being highly variable they are not an appropriate genus-level character. Because of these findings, there appears to no longer be any character that warrants recognition of the three separate genera. Species of Neorhadinorhynchus and Sclerocollum are recombined with Diplosentis because it is the senior synonym of both. Diplosentis manteri Gupta et Fatma, 1979 described from a single specimen from an ariid catfish in India by Gupta and Fatma (1979) and $D$. ikedai Machida, 1992 described from 11 specimens from a labrid in Japan by Machida (1992) appear genuinely to have only two cement glands and must be recombined with different genera (see below).

We propose that Diplosentis (including the new synonyms Neorhadinorhynchus and Sclerocollum) should be considered a part of the Cavisomidae on the basis of its possession of a smooth tegument and four cement glands. This position causes the Diplosentidae to fall into synonymy with the Cavisomidae because the latter has priority.

Synonymy of the Diplosentidae has the implication that the five other genera in this family should be placed in new or other families. We suggest that the position of these genera receives further consideration but propose the following solutions for the present. We agree with Araki and Machida (1987) that Allorhadinorhynchus should be considered a synonym of Micracanthorhynchina in the Rhadinorhynchidae. We have examined Yamaguti's type material of Allorhadinorhynchus segmentatum and the vouchers lodged in the NSMT by Araki and Machida. The number of cement glands in the type material is difficult to determine. The vouchers, however, are clearer and we agree with Araki and Machida (1987) that this species possesses four cement glands. We propose that Golvanorhynchus should also be moved to the Rhadinorhynchidae for the present time in light of its possession of six cement glands and trunk spines. This move is reliant on the description by Noronha et al. (1978) being accurate and the acceptance of Amin's (1985) classification (but see discussion on the Rhadinorhynchidae below): the type material of $G$. golvani was unavailable for examination at the time of writing this paper. We propose that Slendrorhynchus be moved to the Rhadinorhynchidae because it has four cement glands, trunk spines and a proboscis comparable to the rhadinorhynchid genera Micracanthorhynchina and Cleaveius Subramanian, 1927. For Amapacanthus we draw attention to the fact that the type species, $A$. amazonicus SalgadoMaldonado et Santos, 2000 shows significant similarity to Caballerorhynchus lamothei Salgado-Maldonado, 1977 and Pseudogorgorhynchus arii Moravec, Wolter et Körting, 1999. These latter species are each reported to have four cement glands whereas A. amazonicus is reported with only two, but the three species are similar, especially in the armature of the proboscis. In addition, all three species are known from South American fishes and all are reported from, in part, ariid catfishes by Salgado-Maldonado (1977), Moravec et al.(1999) and Salgado-Maldonado and Santos (2000). Unfortunately the type material of $A$. amazonicus and $C$. lamothei was unavailable at the time of writing this paper. We suggest that these genera are better placed in the Rhadinorhynchidae but that they will have to be reviewed at a later date when specimens become available for further study.

Unlike the other genera, Pararhadinorhynchus does not fit easily into another family of acanthocephalans. We have re-examined type material of the type species, P. mugilis Johnston et Edmonds, 1947 and the second species $P$. coorongensis Edmonds, 1973 and confirm the key characters of the genus of only two cement glands and a smooth trunk. These two species, $P$. upenei Wang, Wang et $\mathrm{Wu}, 1993$ and the two other species of Diplosentis, D. ikedai and D. manteri which also have 
only two cement glands, do not fit convincingly in any present family of Acanthocephala.

Here we propose two new genera of acanthocephalans, each with only two cement glands. One of these genera, Transvena gen. n., is proposed as the basis for a new family, Transvenidae, containing Transvena gen. n., Trajectura gen. n. and Pararhadinorhynchus.

\section{Transvenid a e fam. $n$.}

Family diagnosis. Palaeacanthocephala. Echinorhynchida. Small to medium-sized worms. Females may be larger than males. Trunk cylindrical to fusiform, with either a single ring of spines at anterior end of trunk or completely without spines; females may have distinct lateral conical projection at anterior end of trunk; paired protrusions may be present on ventro-posterior end of trunk of males. Proboscis claviform to cylindrical with longitudinal rows of hooks. Proboscis hooks decrease in length from apex to base of proboscis, although apical hooks slightly smaller than subapicals. Proboscis receptacle double-walled; ganglion mid-proboscis receptacle. Lemnisci 2, variable in shape and length but not extending beyond anterior testis. Male reproductive system occupies half or more of trunk. Testes 2, roughly ovoid or elongate. Cement glands always 2, pyriform or tubular. Seminal vesicle present. Säfftigen's pouch present. Female reproductive system: vagina relatively short, sphincter present, uterus tubular, selector apparatus present, uterine bell tubular but usually obscured by eggs. Eggs fusiform with polar extension of E2 membrane. Parasites in intestines of marine fishes.

In c luded ge nera: Transvena gen. n., Trajectura gen. n., Pararhadinorhynchus.

Ty p e ge nu s: Transvena gen. $\mathrm{n}$.

Remarks. To our knowledge, no other acanthocephalan family has only two cement glands.

\section{Transvena gen. $\mathrm{n}$.}

Diagnosis. Trunk with single ring of posteriorly pointing spines, at or near junction between neck and trunk; prominent paired protrusions at ventro-posterior end of trunk on males; females without conical projection on trunk. Proboscis claviform. Proboscis hooks decrease considerably in length from apex to base of proboscis, although apical hooks smaller and more slender than subapicals. Proboscis receptacle doublewalled. Ganglion near middle of proboscis receptacle. Lemnisci extend beyond posterior margin of proboscis receptacle when proboscis everted. Male reproductive system occupies more than half of trunk. Cement glands 2. Säfftigen's pouch present. Seminal vesicle present. Parasites in intestines of marine fishes.

$\mathrm{T}$ y $\mathrm{p}$ e $\mathrm{s}$ p e c i e s : Transvena annulospinosa sp. n. from Anampses neoguinaicus Bleeker, 1878 (Labridae), Australia.

In c luded species: None other.
E $\mathrm{t}$ y $\mathrm{m} \mathrm{o} l \mathrm{og}$ y : The name refers to a newcomer to acanthocephalan taxonomy; transvena one who comes over from another place - a newcomer, stranger, foreigner.

Remarks. The presence of two cement glands in combination with a ring of spines on the trunk is sufficient to distinguish this genus from all other acanthocephalan genera.

\section{Transvena annulospinosa sp. $\mathrm{n}$.}

Figs. 1-10

Description (general description based on 30 male and 32 female wholemounts, 1 worm sectioned and 1 worm for SEM, all from Anampses neoguinaicus, Heron Island; 11 males and 10 females were measured):

GENERAL: Body small. Females slightly larger than males. Trunk thick-walled, with one ring of very small spines at or near junction of neck and trunk. Trunk spines robust, 8.6-11 (10.3) long; approximately 63 on ring; each spine embedded in trunk wall. Proboscis claviform with 12-14 longitudinal rows of hooks; each row with 6-8 hooks (usually 6-7). Proboscis hooks decrease in size from apex (= hook 1$)$ to base although hooks 1 smaller than subapicals: hooks 1-4 32-98 (71); hooks 5-7 16-36 (21); roots not observable. Neck present. Ganglion near middle of proboscis receptacle. Proboscis receptacle double-walled. Lemnisci equal in length, extending beyond posterior margin of proboscis receptacle when proboscis everted. Genital pores subterminal.

MALES: Trunk fusiform, 1,248-2,320 $(1,695) \times 288$ 592 (401). Ring of trunk spines 25-114 (65) from anterior margin of trunk. Proboscis 208-398 (283) × 95196 (129). Proboscis hooks: hooks 1-4 32-98 (70); hooks 5-7 16-36 (21). Neck 44-189 (155) × 107-208 (155). Proboscis receptacle 353-656 (499) $\times$ 82-164 (120). Lemnisci 473-776 (601) × 50-120 (90). Testes 2 , one slightly more anterior than other; anterior testis 208$599(357) \times 120-278(194), 400-768$ (565) from anterior margin of trunk; posterior testis 196-555 (323) $\times 133$ 271 (199). Cement glands tubular to pyriform, 85-221 (175) wide. Protrusions paired, at ventro-posterior end of trunk, 63-126 (93) (perpendicular height) $\times 120-322$ (192) (width of base) (Figs. 1, 8, 9). Säfftigen's pouch between cement glands, 69-208 (115) wide. Seminal vesicle irregularly tubular, may extend to margin of posterior testis.

FEMALES: Trunk fusiform, 1,600-3,664 (2,362) $\times$ 352-592 (484). Ring of trunk spines 63-107 (83) from anterior margin of trunk. Proboscis 221-360 (294) $\times$ 114-196 (151). Proboscis hooks: hooks 1-4 32-98 (71); hooks 5-7 16-28 (21). Neck 95-221 (162) × 120-265 (197). Proboscis receptacle 410-726 (566) $\times 82-246$ (145). Lemnisci 454-959 (582) $\times \quad$ 69-133 (95). Reproductive system (only one specimen measured): uterine bell obscured by eggs; selector apparatus 80 long; uterus 336 long, tubular; vaginal sphincter present; vagina 50 , short. Genital pore subterminal, recessed in 
1

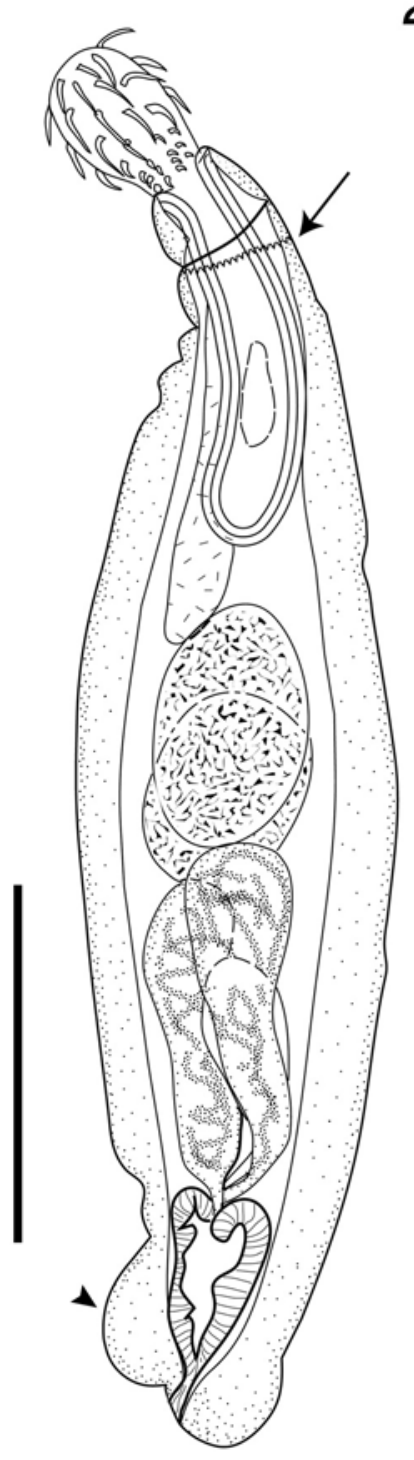

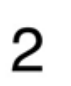
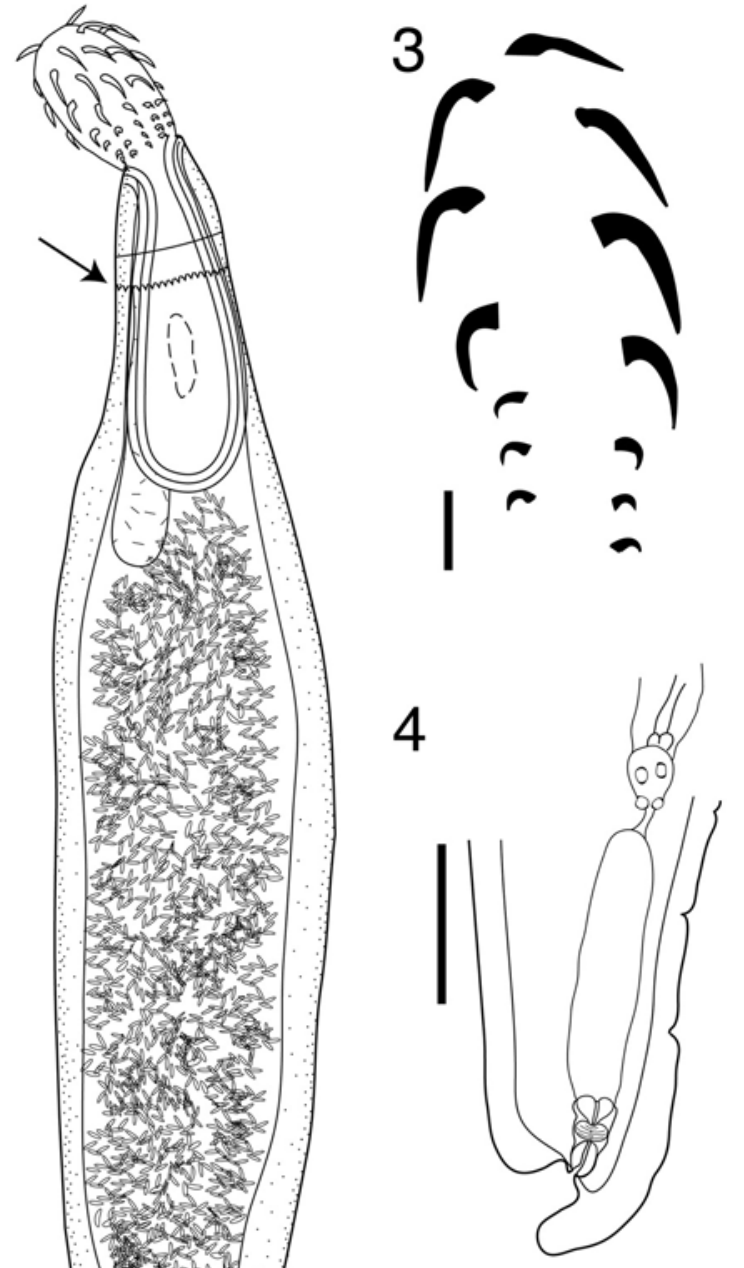

5

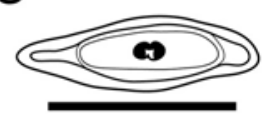

Figs. 1-5. Transvena annulospinosa sp. n. from Anampses neoguinaicus. Fig. 1. Lateral view of a male specimen (holotype); arrowhead points to protrusions on trunk. Fig. 2. Lateral view of a female specimen. Arrows in Figs. 1 and 2 point to the ring of spines on the trunk. Fig. 3. Proboscis hooks showing one longitudinal row with 7 hooks and the other with 6 . Fig. 4. Reproductive system of female (paratype) showing the uterine bell, selector apparatus, uterus, sphincter and vagina. Fig. 5. Egg. Scale bars: Figs. 1, $2=500 \mu \mathrm{m}$; Fig. $3=50 \mu \mathrm{m}$; Fig. $4=200 \mu \mathrm{m}$; Fig. $5=50 \mu \mathrm{m}$.

trunk. Eggs fusiform with polar extensions of E2 membrane, 62-66 (64) × 13-19 (16).

T y p e s p e c i m e n s : holotype (QM G 218206); paratypes from type host (QM G 218207-218215).

$\mathrm{T}$ y p e h o s t: Anampses neoguinaicus Bleeker, 1878 (Labridae).

$\mathrm{O} t \mathrm{~h}$ e $\mathrm{r}$ h o s t s : All Labridae ex Heron I.: Anampses caeruleopunctatus Rüppell, 1829, A. geographicus Valenciennes, 1840, Hemigymnus fasciatus (Bloch, 1792), $H$. melapterus (Bloch, 1791), Thalassoma jansenii (Bleeker, 1856), and T. lunare (Linnaeus, 1788).
T y p e 1 o c a 1 i t y : Heron Island, Queensland, Australia $\left(23^{\circ} 27^{\prime} \mathrm{S}, 151^{\circ} 55^{\prime} \mathrm{E}\right)$.

$\mathrm{S}$ i t e of in fection: Intestine.

P r e v a 1 e n c e : Transvena annulospinosa was recovered from the following labrids from waters around Heron Island: 18 of 59 Anampses neoguinaicus, 1 of 1 A. caeruleopunctatus, 1 of 4 A. geographicus, 9 of 23 Hemigymnus fasciatus, 1 of $22 \mathrm{H}$. melapterus, 1 of 7 Thalassoma jansenii, and 1 of 275 T. lunare. 


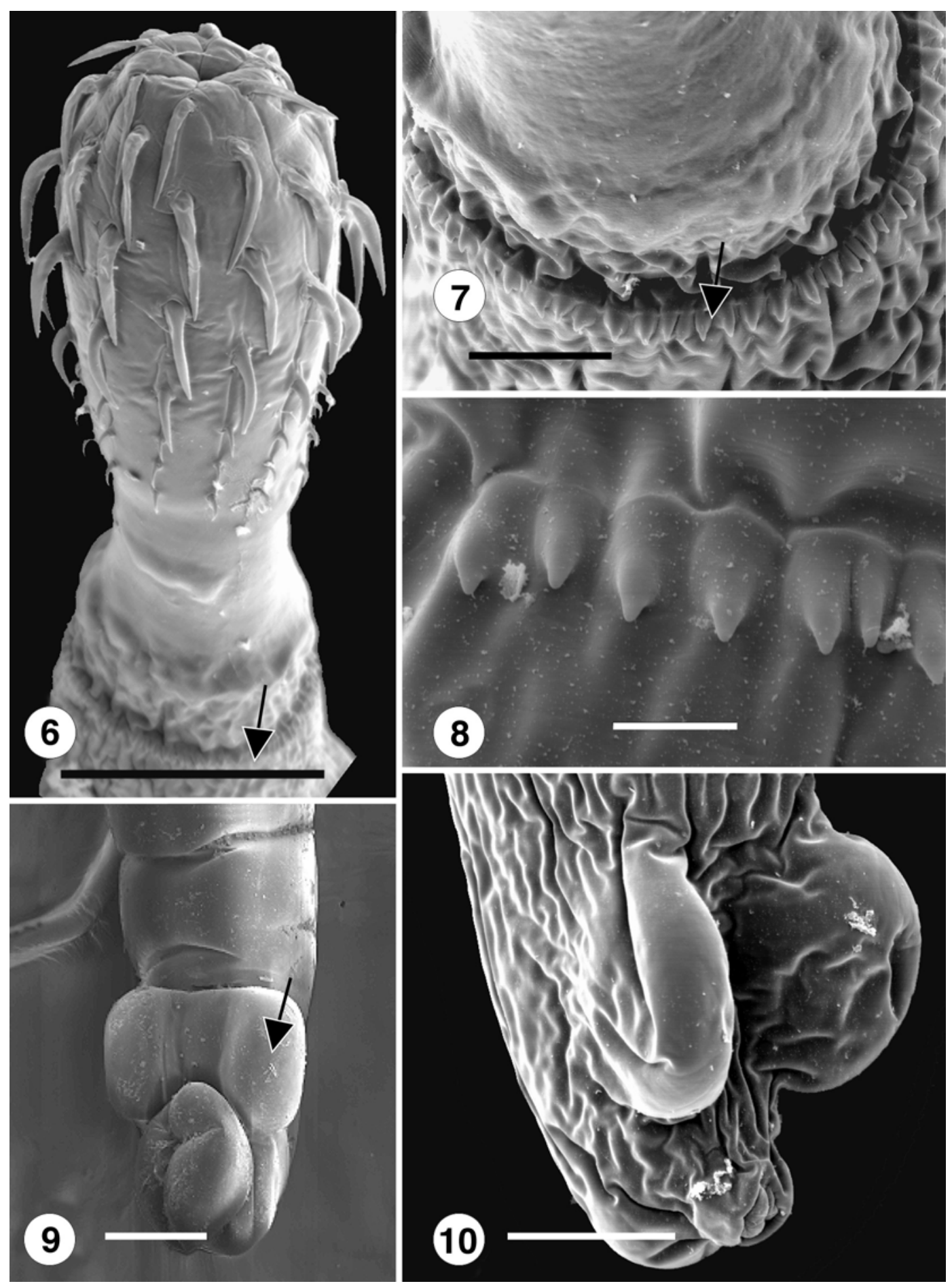

Figs. 6-10. Scanning electron microscope images of male specimens of Transvena annulospinosa sp. n. Fig. 6. Anterior part of worm showing proboscis hooks and position of ring of spines on the trunk (arrow). Figs. 7, 8. Ring of spines (arrow). Fig. 9. En face view of paired protrusions (arrow) on the posterior end of the trunk of a specimen recovered from Hemigymnus fasciatus. Fig. 10. Lateral view of protrusions of a specimen recovered from Anampses neoguinaicus. Note: wrinkled appearance due to specimen processing. Scale bars: Figs. 6, 9, $10=100 \mu \mathrm{m}$; Fig. $7=30 \mu \mathrm{m}$; Fig. $8=10 \mu \mathrm{m}$. 
M a t e r i a 1 e x a m in e d: 64 worms from A. neoguinaicus, 3 from A. caeruleopunctatus, 1 from A. geographicus, 27 from Hemigymnus fasciatus, 1 from $H$. melapterus, 1 from Thalassoma jansenii, and 1 from T. lunare.

E $\mathrm{t}$ y $\mathrm{m}$ o 1 o g y: The name annulospinosa refers to the distinctive ring of spines on the trunk.

Remarks. The ring of spines on the trunk is not a broad band of spines as in Amapacanthus SalgadoMaldonado et Santos, 2000 but a single row (see Figs. 1, 2, 7, 8). The proboscis armature of Transvena most closely resembles that of the rhadinorhynchids Micracanthorhynchina Strand, 1936 and Cleaveius in that there is a noticeable decrease in length of the hooks from the apex to the base of the proboscis. The rhadinorhynchids, however, have four cement glands and a broad band of spines on the trunk. The number of cement glands in Transvena annulospinosa was confirmed by examining transverse sections through a male specimen. The single ring of spines on the trunk of Transvena further distinguishes this new genus from these genera.

The function of the paired protrusions on the males is unknown. They appear to be robust projections. Specimens were collected from several fish from several localities around Heron Island and at different times of the year and all the male worms had the protrusions. The male bursa appears to be typical of other acanthocephalans. The paired protrusions were prominent in all live and fixed specimens so that they do not appear to be temporary structures. These protrusions may aid in clasping the female, which has a subterminal genital pore.

No specimen of Transvena annulospinosa was recovered from five Thalassoma hardwicke (Bennett, 1830) from Heron Island. The two infected species of Thalassoma Swainson, 1839 only had one immature worm each. The species of Thalassoma are probably not primary or normal hosts for T. annulospinosa. Species of Anampses Quoy et Gaimard, 1824 and Hemigymnus Günther, 1861 are often seen feeding at the same sites at Heron Island and all species were parasitised with gravid females except the one infected $H$. melapterus in which only a single mature male specimen was recovered.

\section{Trajectura gen. n.}

Diagnosis. Trunk without spines. Proboscis cylindrical to slightly claviform. Proboscis hooks decrease in length from apex to base of proboscis although apical hooks smaller than subapicals. Proboscis receptacle double-walled. Ganglion midproboscis receptacle. Lemnisci extend beyond posterior margin of proboscis receptacle when proboscis fully everted. Male reproductive system occupies more than half of trunk. Cement glands 2, pyriform. Conical projection lateral, at anterior end of trunk of female, level with posterior margins of lemnisci. Males without paired protrusions on ventro-posterior end of trunk. Seminal vesicle present. Säfftigen's pouch present. Parasites in intestines of marine fishes.

$\mathrm{T}$ y $\mathrm{p}$ e $\mathrm{s}$ p e c i e s : Trajectura perinsolens $\mathrm{sp}$. $\mathrm{n}$. from Anampses neoguinaicus, Australia.

I n c 1 u d e d s p e c i e s : Diplosentis ikedai Machida, 1992 from Cirrhilabrus cyanopleura, Japan also belongs to this genus because of the presence of the conical projection: Trajectura ikedai (Machida, 1992) comb. n. is therefore proposed.

E t y m o log y: The name refers to the conical projection on the female trunk; trâjectûra projecting over, projection.

Remarks. The presence of two cement glands in combination with the conical projection on the female trunk is sufficient to distinguish this genus from all other acanthocephalan genera. However, Trajectura can also be easily distinguished from Transvena in that it lacks spines on its trunk. Pararhadinorhynchus has a pair of long tubular cement glands and the male reproductive organs occupy about half of the posterior end of the trunk whereas Trajectura has club-shaped or pyriform cement glands and its reproductive organs occupy most of the trunk.

Trajectura perinsolens sp. $\mathrm{n}$.

Figs. 11-21

Description (general description based on 19 male and 18 female wholemounts, 1 worm sectioned and 1 worm for SEM, all from Anampses neoguinaicus, Heron Island; 17 males and 11 females were measured.)

GENERAL: Females considerably larger than males. Trunk thick-walled; trunk spines absent. Proboscis cylindrical to slightly claviform with 13-14 longitudinal rows; each row with 7-9 hooks; roots not observable. Proboscis hooks: apical hooks slightly smaller and more slender than subapicals; last 3 basal hooks usually small and sometimes strongly curved; hooks 1-4 (apical hooks) 43-65 (55); hook 5 22-55 (40); hook 6 16-32 (23); hooks 7-9 13-24 (17). Ganglion mid-proboscis receptacle. Proboscis receptacle double-walled. Lemnisci 2, equal, extend beyond posterior margin of proboscis receptacle when proboscis fully everted.

MALES: Trunk fusiform 1,312-3,040 $(2,185) \times 82-$ 512 (243). Proboscis 265-410 (329) × 76-158 (116). Proboscis hooks: hook 1-4 (apical hooks) 43-62 (53); hook 5 22-55 (42); hook 6 17-32 (23); hooks 7-9 (basal hooks) 13-24 (19). Proboscis receptacle 334-599 (488) $\times 76-177$ (137). Lemnisci 284-800 (606) × 69-176 (124). Testes 2, tandem; anterior testis 265-656 (443) $\times 139-290$ (244); posterior testis 265-587 (431) × 107303 (205). Cement glands 2, pyriform, 95-316 (208) wide. Bursa when everted 208-252 (230) × 139-196 (168). Säfftigen's pouch 112-173 (142) $(\mathrm{n}=3) \times 42-163$ (103) $(\mathrm{n}=2)$. Seminal vesicle long, between cement glands. Paired protrusions on posterior end absent. Genital pore only slightly subterminal. 


\section{1}

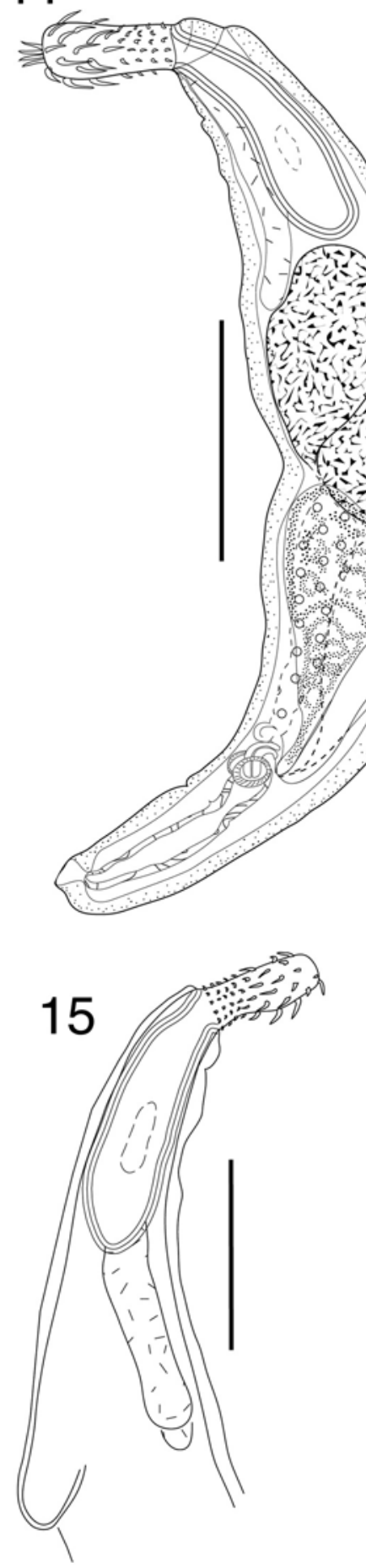

14

12
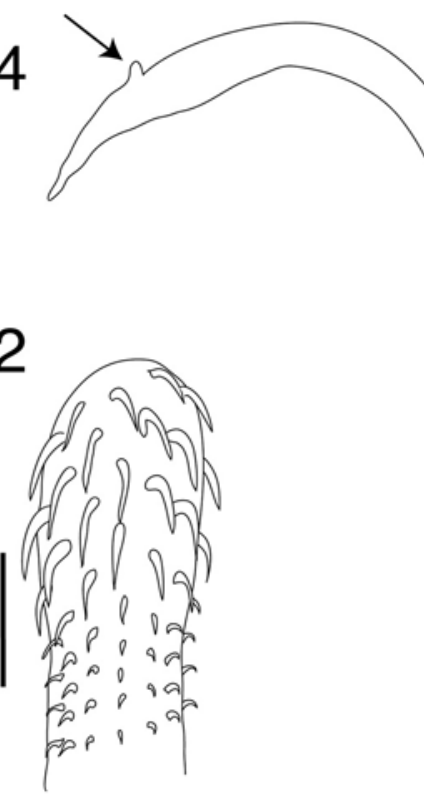

16

13
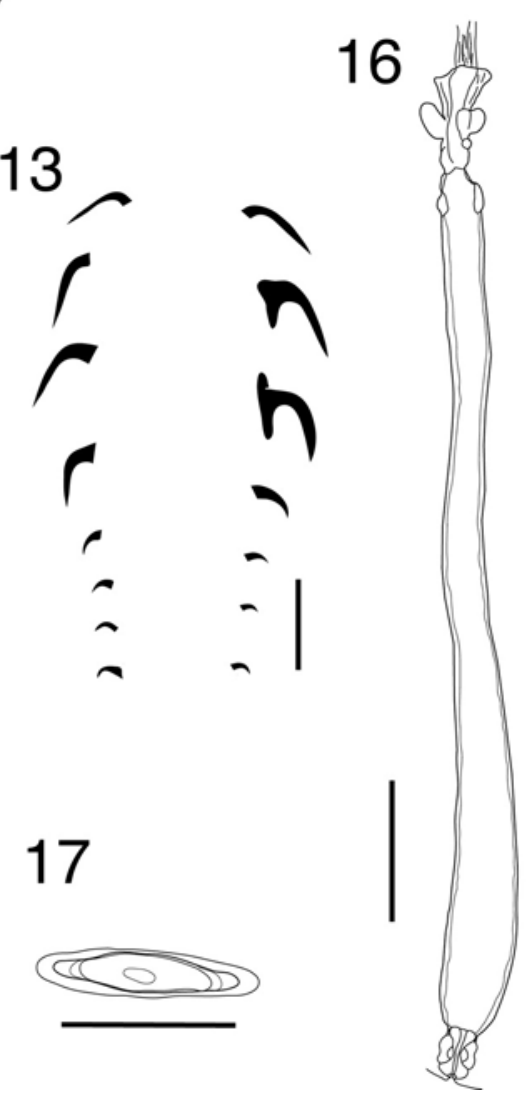

Figs. 11-17. Trajectura perinsolens sp. n. from Anampses neoguinaicus. Fig. 11. Lateral view of male specimen (holotype). Fig. 12. Proboscis of a male specimen (paratype). Fig. 13. Proboscis hooks of a paratype. Fig. 14. Female specimen (paratype) outline showing conical projection (arrow) on the anterior of the trunk. Fig. 15. Anterior end of female showing conical projection relative to lemnisci. Fig. 16. Uterine bell. Fig. 17. Egg. Scale bars: Figs. $11,14,15=500 \mu \mathrm{m}$; Fig. $12=100 \mu \mathrm{m} ;$ Figs. $13,17=$ $50 \mu \mathrm{m}$; Fig. $16=350 \mu \mathrm{m}$. 
FEMALES: Body cylindrical, very long 9,040-13,920 $(11,480)(\mathrm{n}=2) \times 576(\mathrm{n}=1)$; conical projection on trunk, $184-400(267) \times 128-256$ (185); 720-1,280 $(1,053)$ from anterior end of trunk, at about level of posterior ends of lemnisci. Proboscis 164-467 (367) $\times$ 63-151 (126). Proboscis hooks: hooks 1-4 (apical hooks) 49-65 (57); hook 5 22-44 (33); hook 6 16-22 (20); hooks 7-9 (basal hooks) 14-19 (17). Proboscis receptacle 581-864 (727) × 126-246 (182). Lemnisci 1,088-1,104 $(1,096) \times 144-160(152)$. Female reproductive system (one specimen measured only): uterine bell short; selector apparatus present; uterus long, tubular, 2,160 long; vaginal sphincter present; vagina short. Genital pore terminal. Eggs 58-71 (65) × 13-16 (14).

Remarks. All females examined in this study had a conical projection on their trunks. This structure was always present in live material and remained after being fixed. Thus, it is not an artifact of fixation. The projections differed little between specimens except to be larger or smaller proportionally to the size of the trunk. It was always situated at the same place on the trunk relative to the lemnisci regardless of the size of the worm. It also does not appear to be related to the maturity of the worm, as both small immature and adult gravid females had this projection.

Only this new species, Trajectura ikedai comb. $\mathrm{n}$. and Femogibbosus assi Paruchin, 1973 have a conical projection of the trunk on the female (see above, Machida (1992) and Paruchin (1973) respectively). The function of this structure is unknown in all three species. No opening was seen in the structure in $T$. perinsolens nor were eggs or other material observed to escape from this structure in live worms. F. assi has four very long tubular cement glands which easily distinguishes it from the two species of Trajectura which have only two shorter more pyriform cement glands.

Trajectura perinsolens can be distinguished from $T$. ikedai in having more longitudinal rows of hooks, longer hooks on the proboscis and larger eggs. The longest hooks on the proboscis are up to $44 \mu \mathrm{m}$ for $T$. ikedai according to Machida (1992) and $65 \mu \mathrm{m}$ for $T$. perinsolens. The eggs of $T$. ikedai are 45-53 $\mu \mathrm{m}$ long whereas they are $68-71 \mu \mathrm{m}$ for $T$. perinsolens. Trajectura perinsolens and another transvenid, Transvena annulospinosa were occasionally recovered from the same host individuals.

T y p e s pe c i m e n s : holotype (QM G 218216); paratypes (QM G 218217-218231).

$\mathrm{T}$ y $\mathrm{p}$ e $\mathrm{h}$ o s t : Anampses neoguinaicus Bleeker, 1878 (Labridae).

Other hosts: None.

T y p e 1 o c a 1 i t y : Heron Island, Queensland, Australia $\left(23^{\circ} 27^{\prime} \mathrm{S}, 151^{\circ} 55^{\prime} \mathrm{E}\right)$.

$\mathrm{S}$ i t e : Intestine.

$\mathrm{P} \mathrm{r}$ e v a $1 \mathrm{e} \mathrm{n}$ c e : 43 Trajectura perinsolens were recovered from 18 of the 59 Anampses neoguinaicus examined.
M a t e r i a 1 e x a m in ed: 39 worms from A. neoguinaicus, Heron Island.

E $\mathrm{t} y \mathrm{~m} \mathrm{o} 1 \mathrm{og} \mathrm{y}$ : The name refers to the unusual conical projection on the female's trunk: per-insolens very unusual.

\section{Pararhadinorhynchus Johnston et Edmonds, 1947}

Johnston and Edmonds (1947) described Pararhadinorhynchus mugilis from a mullet, Mugil cephalus Linnaeus, 1758 in South Australia. Edmonds (1973) subsequently described another species, Pararhadinorhynchus coorongensis also from South Australia but from a different mullet, Aldrichetta forsteri (Valenciennes, 1836). Both species were said to possess two cement glands. However, Johnston and Edmonds (1947) described the ducts of the cement glands as forming two long cement reservoirs. As cement reservoirs are usually not associated with palaeacanthocephalans we examined the type material of both species to check that they have only two cement glands. We examined the holotype, paratypes and vouchers of $P$. mugilis and $P$. coorongensis (museum numbers listed in Materials and Methods). The type material of both species appears to have two long tubular cement glands but the tubular nature of the cement glands, especially the constriction in the middle, which many specimens seem to have, renders interpretation difficult. We also examined the transverse sections of $P$. mugilis (AHC 42422-42425) used by Johnston and Edmonds (1947). If four cement glands were present we would have expected to find evidence either of four cement glands or a combination of two cement glands and two cement gland ducts in a section. Neither was seen, supporting the interpretation of only two cement glands by Johnston and Edmonds (1947). Thus, we consider that Pararhadinorhynchus is a valid genus.

Currently there are three species of Pararhadinorhynchus: P. mugilis, P. coorongensis, and P. upenei. A species described as Diplosentis manteri by Gupta and Fatma (1979) is also here considered to belong to this genus because it has two long tubular cement glands and its proboscis hooks are more reminiscent of this genus than those of Transvena or Trajectura and it does not have trunk spines. Thus, with Pararhadinorhynchus manteri (Gupta et Fatma, 1979) comb. n., there are four species of Pararhadinorhynchus.

\section{Key to genera and species of Transvenidae}

This key is based on information contained in the descriptions for Trajectura ikedai (as Diplosentis ikedai) by Machida (1992), for Pararhadinorhynchus coorongensis by Johnston and Edmonds (1947) and Edmonds (1973), for Pararhadinorhynchus manteri (as Diplosentis manteri) by Gupta and Fatma (1979), for Pararhadinorhynchus mugilis by Edmonds (1973), for Pararhadinorhynchus upenei Wang, Wang et $\mathrm{Wu}, 1993$ by Wang et al. (1993) and from the present study. 

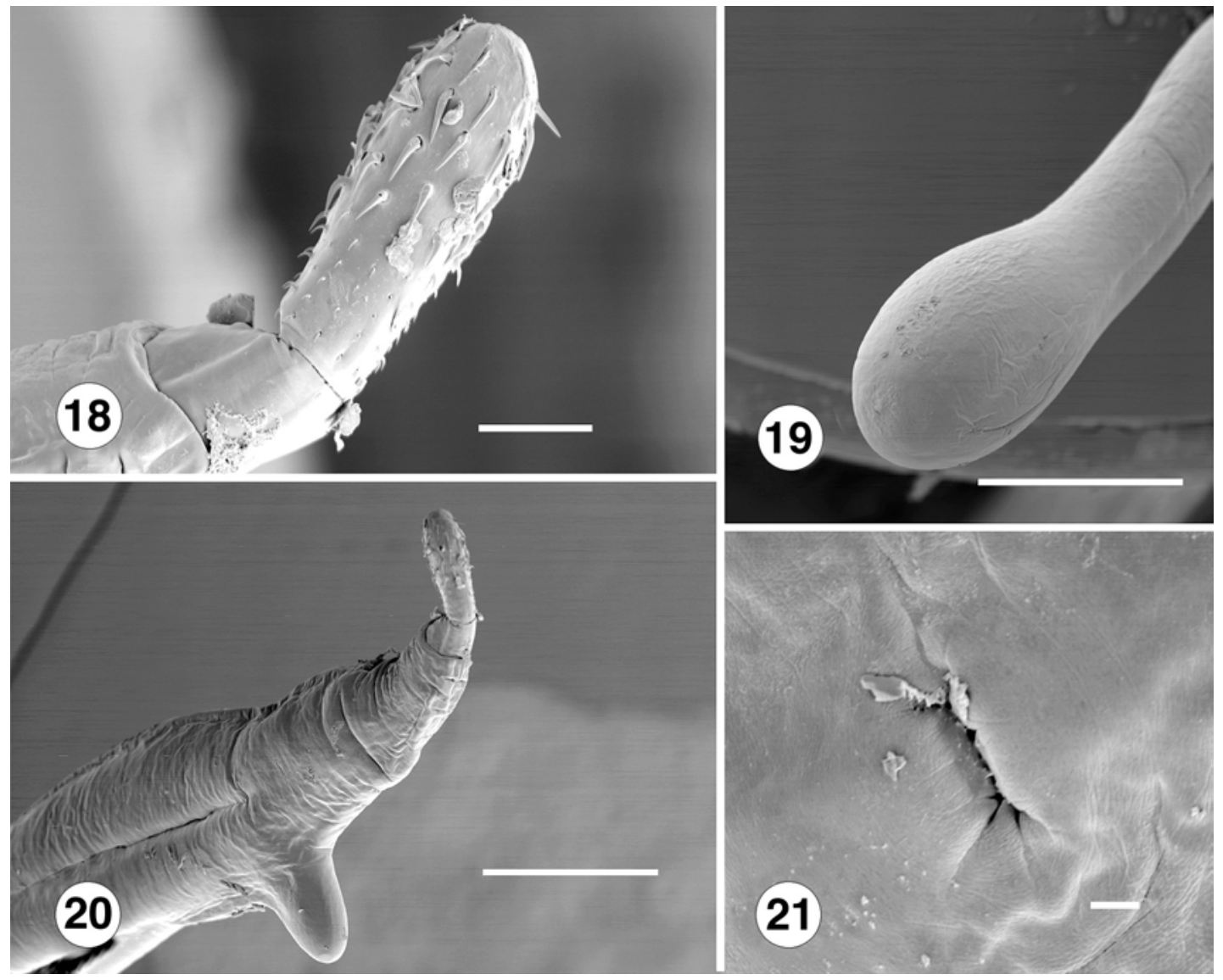

Figs. 18-21. Scanning electron microscope images of female specimens of Trajectura perinsolens sp. n. from Anampses neoguinaicus. Fig. 18. Proboscis. Fig. 19. Posterior end of the trunk. Fig. 20. Anterior of trunk showing position of conical projection. Fig. 21. Genital pore. Scale bars: Fig. $18=100 \mu \mathrm{m}$; Fig. $19=1,000 \mu \mathrm{m}$; Fig. $20=500 \mu \mathrm{m}$; Fig. $21=10 \mu \mathrm{m}$.

1 Spines on trunk present ..... Transvena annulospinosa

- Spines on trunk absent

2 Females with lateral conical projection at level of lemnisci

- Females without conical projection .. 3

3 Largest proboscis hook less than $45 \mu \mathrm{m}$ long Trajectura ikedai

- Largest proboscis hook more than $45 \mu \mathrm{m}$ long Trajectura perinsolens

4 Fewer than 14 longitudinal rows of proboscis hooks .. Pararhadinorhynchus manteri

- 14 or more longitudinal rows of proboscis hooks .... 5

510 or fewer hooks per longitudinal row Pararhadinorhynchus coorongensis

- More than 10 hooks per longitudinal row ... 6

6 Fewer than 20 hooks per longitudinal row . Pararhadinorhynchus mugilis

- More than 20 hooks per longitudinal row Pararhadinorhynchus upenei

\section{DISCUSSION}

Acanthocephalans have few stable characters that are useful for family-level taxonomy. In the order Echinorhynchida as it is presently conceived, there are about nine families which are defined by a combination of such characters as the armature of the proboscis, the shape of proboscis, the presence or absence of trunk spines and their arrangement on the trunk, the number and shape of cement glands, the lacunar system, the position of the ganglion in the proboscis receptacle, egg shape, and the nature of nuclei in the body wall. Recently the specificity of the intermediate hosts was shown to be useful in taxonomy but at genus-level (Nickol et al. 1999). Generally, no single character state serves to define echinorhynchidan families alone; a combination of at least two characters is usually required. In addition to the paucity of characters, a significant proportion of taxa appear to have been based on erroneously interpreted characters. The use of the 
presence or absence of trunk spines to help define families of the Echinorhynchida provides good examples of often misinterpreted characters.

The presence or absence of trunk spines is a valuable taxonomic character but if wrongly interpreted can cause considerable difficulty. A major problem relates to the fact that they may be easily lost (Golvan 1969) or overlooked. Recently Pichelin (1999) discovered spines on the type species of Hypoechinorhynchus Yamaguti, 1939, H. alaeopis Yamaguti, 1939, that had been overlooked previously. As a result, although the genus remained valid, the family Hypoechinorhynchidae Golvan, 1960 was made a synonym of Arhythmacanthidae Yamaguti, 1935 because of the overlap between the two family diagnoses once the absence of trunk spines was no longer a valid criterion for separation of the two families. This is not an isolated case. Therefore, whereas trunk spines are a useful character, their misinterpretation may be seriously misleading.

The use of the number of cement glands in defining families of the Echinorhynchida has been controversial. Amin (1985) criticised Golvan (1969) for placing too much importance on the number of cement glands in his classification. However, Amin chose to order his list of species according to the Meyer-Van Cleave system as expanded by Bullock (1969) despite the fact that Van Cleave (1949) considered the shape, number and structure of the cement glands to be sound morphological features of value in taxonomy of genera and higher taxonomic categories. In our view the character has been unreasonably devalued because of confusion in the literature which relates mainly to problems with counting the number of cement glands. Confusion has sometimes been perpetuated even when published accounts have corrected misinterpretations made originally. This is particularly relevant for the family Rhadinorhynchidae Travassos, 1923. According to Cable and Linderoth (1963) the number of cement glands in the type species of the type genus, Rhadinorhynchus pristis (Rudolphi, 1802) Lühe, 1911, was not given in the original description but Chandler (1934) assumed that it must have had eight. Van Cleave and Lincicome (1940) considered that the concept of the genus Rhadinorhynchus and of the family had changed over time and needed to be reconsidered. They restricted the family Rhadinorhynchidae to those genera having eight cement glands. At the same time, they created the family Gorgorhynchidae Van Cleave et Lincicome, 1940 for those rhadinorhynchids with four cement glands. Golvan (1960) added the subfamily Illiosentinae Golvan, 1960 (including Illiosentis Van Cleave et Lincicome, 1939 and Telosentis Van Cleave, 1923) and included the subfamilies Rhadinorhynchinae Lühe, 1912 (including Rhadinorhynchus, Tegorhynchus Van Cleave, 1921, and Hemirhadinorhynchus Krotov et Petrotschenko, 1956 which is now a synonym of
Pseudorhadinorhynchus) and Leptorhynchoidinae Witenberg, 1932 (including only Leptorhynchoides Kostylew, 1924). However, both Van Cleave and Lincicome (1940) and Golvan (1960) based their taxonomic accounts on the flawed assumption made by Chandler (1934) that the type of Rhadinorhynchus had eight cement glands. Cable and Linderoth (1963) showed that this assumption was incorrect. They emended the diagnosis of Rhadinorhynchus stating that it has only four cement glands. Golvan (1969) accepted the findings of Cable and Linderoth (1963) and placed his illiosentine genera in the Illiosentidae Golvan, 1960 along with Pseudorhadinorhynchus and other genera that possessed eight cement glands and spines on the trunk. Golvan (1969) also placed Leptorhynchoides into the Leptorhynchoididae Witenberg, 1932 along with Metacanthocephalus Yamaguti, 1959 because both genera possessed eight cement glands and no trunk spines. On account of the discovery by Cable and Linderoth (1963) that Rhadinorhynchus has only four cement glands, Golvan (1969) proposed that the Rhadinorhynchidae contain only genera with four cement glands and trunk spines; these were Rhadinorhynchus, Raorhynchus Tripathi, 1959, Megistacantha Golvan, 1960, Cathayacanthus Golvan, 1969, Paragorgorhynchus Golvan, 1957, Gorgorhynchus Chandler, 1934, Cleaveius, Micracanthorhynchina, Australorhynchus Lebedev, 1967 and Serrasentis Van Cleave, 1923. Golvan's classification for this group appeared taxonomically sound. Although Golvan (1969) defined explicitly the rhadinorhynchids as possessing four cement glands and trunk spines, Amin (1985) either placed or retained (it is not clear which) in the Rhadinorhynchidae several genera with eight cement glands and no trunk spines (i.e. Leptorhynchoides, Metacanthocephalus, Pseudoleptorhynchoides SalgadoMaldonado, 1977), Metacanthocephaloides Yamaguti, 1959 with six cement glands and no trunk spines and Gorgorhynchoides Cable et Linderoth, 1963 with six cement glands and trunk spines. As far as we can deduce, there was no basis for Amin (1985) to list genera with more than four cement glands in the Rhadinorhynchidae other than the wide range of cement gland number for the family which was based on the previous misunderstanding of the number of cement glands. The three genera with eight cement glands and no trunk spines had been assigned to their own family, the Leptorhynchoididae, which appears to form a natural group. Metacanthocephaloides with six cement glands and no trunk spines should probably be returned to the Echinorhynchidae where it was placed originally by Yamaguti (1959). Gorgorhynchoides and Golvanorhynchus, which have six cement glands and trunk spines, might be better placed in their own family.

The Diplosentidae has clearly suffered a complex history because of the failure for the number of cement glands in its members to be understood properly. The 
original misinterpretation of the number of cement glands of the type species was unfortunate but the subsequent addition of genera which did not have the same number of cement glands (or any other substantial unifying character) was unjustified. With the disappearance of the Diplosentidae through synonymy as identified in this study, there is now no family in the order Echinorhynchida other than the Rhadinorhynchidae that has genera with different numbers of cement glands, and as discussed above, that family is also defined weakly. Thus, in our view the number of cement glands has considerable value for the recognition of acanthocephalan families. Whereas we recognise that there is room for considerable refinement of familylevel taxonomy in the Echinorhynchida, it is our view that the recognition of the Transvenidae for acanthocephalans of marine fishes with only two cement glands will be a useful concept.

We hope to have shown that the number of cement glands is a useful family-level character within the
Echinorhynchida but that its usefulness has been masked by inaccurate or unjustified taxonomic decisions. We also acknowledge that there are other characters worthy of consideration and that the number of cement glands should always be considered in conjunction with these when available or when necessary.

Acknowledgements. This research was supported by an Australian Biological Resources Study grant to S.P. (99/ABRS009G). We wish to thank T. Wright, C. Chambers and R. Bray for help in collecting fishes and their parasites. We are grateful to $\mathrm{M}$. Jones for assistance with the scanning electron microscopy, to D. Scott for sectioning specimens and J.R. Arthur, M. Reantaso and N. Lopez for kindly tracking down the fate of specimens from the Philippine Bureau of Science. M. Apthorp kindly assisted with the etymology of the new taxa. We are also grateful to P. Pilitt (USNPC), P. Berents (AM), R. Bray (BMNH), J. Araki (MPM), T. Kuramochi (NSMT), F. Moravec (IPCAS) and J. Forrest (AHC) for lending us museum material.

\section{REFERENCES}

AMIN O.M. 1985: Classification. In: D.W.T. Crompton and B.B. Nickol (Eds.), Biology of the Acanthocephala. Cambridge University Press, Cambridge, pp. 27-72.

AMIN O.M., NAHHAS F.M. 1994: Acanthocephala of marine fishes off Fiji Islands, with descriptions of Filisoma longcementglandatus n. sp., Neorhadinorhynchus macrospinosus n. sp. (Cavisomidae), and gravid females of Rhadinorhynchus johnstoni (Rhadinorhynchidae); and keys to species of the genera Filisoma and Neorhadinorhynchus. J. Parasitol. 80: 768-774.

AMIN O.M., NAHHAS F.M., AL-YAMANI F., ABUHAKIMA R. 1984: On three acanthocephalan species from some Arabian Gulf fishes off the coast of Kuwait. J. Parasitol. 70: 168-170.

AMIN O.M., SEY O. 1996: Acanthocephala from Arabian Gulf fishes off Kuwait, with descriptions of Neoechinorhynchus dimorphospinus sp. n. (Neoechinorhynchidae), Tegorhynchus holospinosus sp. n. (Illiosentidae), Micracanthorhynchina kuwaitensis sp. $\mathrm{n}$. (Rhadinorhynchidae), and Slendrorhynchus breviclaviproboscis gen. n., sp. n. (Diplosentidae); and key to species of the genus Micracanthorhynchina. J. Helminthol. Soc. Wash. 63: 201-210.

ARAKI J., MACHIDA M. 1987: Some acanthocephalans from marine fishes of northern Japan, with descriptions of two new species, Acanthocephaloides ichiharai and $A$. claviformis. Bull. Nat. Sci. Mus., Ser. A (Zool.) 13: 1-11.

ARTHUR J.R., LUMANLAN-MAYO S. 1997: Checklist of the parasites of fishes of the Philippines. FAO Fish. Tech. Pap. 369: 1-102.

BULLOCK W.L. 1969: Morphological features as tools and as pitfalls in acanthocephalan systematics. In: G.D. Schmidt (Ed.), Problems in Systematics of Parasites. University Park Press, Baltimore, Maryland and Manchester, England, pp. 9-45.
CABLE R.M., LINDEROTH J. 1963: Taxonomy of some Acanthocephala from marine fishes with reference to species from Curaçao, N. A., and Jamaica, W. I. J. Parasitol. 49: 706-716.

CHANDLER A.C. 1934: A revision of the genus Rhadinorhynchus (Acanthocephala) with descriptions of new genera and species. Parasitology 26: 352-358.

DIAMANT A. 1989: Ecology of the acanthocephalan Sclerocollum rubrimaris Schmidt and Paperna, 1978 (Rhadinorhynchidae: Gorgorhynchinae) from wild populations of rabbitfish (genus Siganus) in the northern Red Sea. J. Fish Biol. 34: 387-398.

EDMONDS S.J. 1964: Australian Acanthocephala, No. 11. Trans. R. Soc. S. Aust. 88: 41-45.

EDMONDS S.J. 1973: Australian Acanthocephala, No. 14. On two species of Pararhadinorhynchus, one new. Trans. R. Soc. S. Aust. 97: 19-21.

EDUARDO S.L. 1997: A Guide to the Collections of Philippine Type-specimens of Parasitic Protozoa, Helminths, and Arthropods. National Academy of Science and Technology, Philippines, $322 \mathrm{pp}$.

EL-NAFFAR M.K.I., GOBASHY A., EL-ETREBY S.G., KARDOUSHA M.M. 1992: General survey of helminth parasite genera of Arabian Gulf fishes (Coasts of United Arab Emirates). Arab Gulf J. Sci. Res. 10: 99-110.

FISHBASE 2000: FishBase. R. Froese and D. Pauly (Eds.), World Wide Web electronic publication, www.fishbase.org, 26 October 2000.

FUKUI T., MORISITA T. 1938: Notes on the acanthocephalan fauna of Japan. Annot. Zool. Jpn. 17: 567-576.

GEETS A., OLLEVIER F. 1996: Endoparasitic helminths of the whitespotted rabbitfish (Siganus sutor (Valenciennes, 1835)) of the Kenyan coast: distribution within the host population and microhabitat use. Belg. J. Zool. 126: 2136. 
GOLVAN Y.J. 1960: Le Phylum des Acanthocephala Troisième note. La Classe des Palaeacanthocephala (Meyer, 1931) (à suivre). Ann. Parasitol. Hum. Comp. 35: 138-165.

GOLVAN Y.J. 1969: Systématique des Acanthocéphales (Acanthocephala Rudolphi 1801) Première Partie. L'Ordre des Palæacanthocephala Meyer 1931. Premier fascicule. La Super-famille des Echinorhynchoidea (Cobbold 1876) Golvan et Houin 1963. Mém. Mus. Natl. Hist. Nat., Sér. A, Zool. 57: 1-373.

GUPTA N.K., JAIN M. 1979: A note on Filisoma indicum Van Cleave, 1928. Indian J. Parasitol. 3: 135-137.

GUPTA N.K., JAIN M. 1983: On three already known species of the genus Neoechinorhynchus Hamann, 1892 (Acanthocephala) from fish of the Arabian Sea. Acta Parasitol. Pol. 28: 407-416.

GUPTA V., FATMA S. 1979: On three new species of acanthocephalan parasites of marine fishes of Mandapam, Tamil Nadu. Indian J. Helminthol. 31: 45-53.

JOHNSTON T.H., EDMONDS S.J. 1947: Australian Acanthocephala No. 5. Trans. R. Soc. Aust. 71: 13-19.

MACHIDA M. 1992: A new species of the genus Diplosentis (Acanthocephala, Diplosentidae) from a wrasse of southern Japan. Jpn. J. Parasitol. 41: 37-39.

MARTENS E., MOENS J. 1995: The metazoan ecto- and endoparasites of the rabbitfish, Siganus sutor (Cuvier and Valenciennes, 1835) of the Kenyan coast. I. Afr. J. Ecol. 33: 405-416.

MORAVEC F., WOLTER J., KÖRTING W. 1999: Some nematodes and acanthocephalans from exotic ornamental freshwater fishes imported into Germany. Folia Parasitol. 46: 296-310.

NICKOL B.B., CROMPTON D.W.T., SEARLE D.W. 1999: Reintroduction of Profilicollis Meyer, 1931, as a genus in Acanthocephala: significance of the intermediate host. J. Parasitol. 85: 716-718.

NORONHA D., de FABIO S.P., PINTO R.M. 1978: Golvanorhynchus golvani gen. n. sp. n. (Palaeacanthocephala, Allorhadinorhynchinae). Atas Soc. Biol. Rio de J. 19: 63-64.

PARUCHIN A. 1973: Femogibbosus assi nov. gen. et spec., ein neuer Kratzer aus dem Indik. Angew. Parasitol. 14: 1823.
PICHELIN S. 1999: Hypoechinorhynchus robustus sp. n. from Notolabrus parilus (Labridae) from Western Australia with a discussion on the validity of the Hypoechinorhynchidae (Acanthocephala: Palaeacanthocephala). Folia Parasitol. 46: 311-315.

SALGADO-MALDONADO G. 1977: Acantocéfalos de peces I. Descripción de Caballerorhynchus lamothei gen. nov. sp. nov. (Acanthocephala: Fessisentidae) parásito de Diapterus olisthostomus de Sontecomapan, Veracruz, México. Excerta Parasitol. mem. del doctor Eduardo Caballero y Caballero 4: 493-501.

SALGADO-MALDONADO G., SANTOS C.P. 2000: Amapacanthus amazonicus n. g., n. sp. (Acanthocephala: Diplosentidae: Allorhadinorhynchinae) from Arius passany and Anableps microleps (Pisces) at Maraca Island off northern Brazil. Syst. Parasitol. 46: 111-116.

SCHMIDT G.D., PAPERNA I. 1978: Sclerocollum rubrimaris gen. et sp. n. (Rhadinorhynchidae: Gorgorhynchinae), and other Acanthocephala of marine fishes from Israel. J. Parasitol. 64: 846-850.

TUBANGUI M.A., MASILUÑGAN V.A. 1937: Diplosentis amphacanthi gen. et sp. nov., an Acanthocephala parasitic in a marine fish. Philippine J. Sci. 62: 183-187.

VAN CLEAVE H.J. 1949: Morphological and phylogenetic interpretations of the cement glands in the Acanthocephala. J. Morphol. 84: 427-458.

VAN CLEAVE H.J., LINCICOME D.R. 1940: A reconsideration of the acanthocephalan family Rhadinorhynchidae. J. Parasitol. 26: 75-81.

WANG Y., WANG P., WU D. 1993: On some Echinorhynchoidea parasites from marine fishes of Fujian Province, China. Wuyi Sci. J. 10: 29-39. (In Chinese.)

WOODLAND D.J. 1990: Revision of the Fish Family Siganidae with Descriptions of Two New Species and Comments on Distribution and Biology. B. P. Bishop Museum, Honolulu, 136 pp.

YAMAGUTI S. 1939: Studies on the helminth fauna of Japan. Part 29. Acanthocephala, II. Jpn. J. Zool. 8: 317-351.

YAMAGUTI S. 1959: Studies on the helminth fauna of Japan. Part 55. Four new genera of Acanthocephala from fishes. Publ. Seto Mar. Biol. Lab. 7: 319-326.

YAMAGUTI S. 1963: Systema Helminthum. Volume V: Acanthocephala. Interscience Publishers, New York, London, $423 \mathrm{pp}$.

Accepted 5 April 2001 